\title{
Using Incidental Teaching to Teach Mands to Children with Autism Spectrum Disorder
}

Katherine Louise South Robinson

Follow this and additional works at: https://researchrepository.wvu.edu/etd

\section{Recommended Citation}

Robinson, Katherine Louise South, "Using Incidental Teaching to Teach Mands to Children with Autism Spectrum Disorder" (2018). Graduate Theses, Dissertations, and Problem Reports. 6518.

https://researchrepository.wvu.edu/etd/6518

This Dissertation is protected by copyright and/or related rights. It has been brought to you by the The Research Repository @ WVU with permission from the rights-holder(s). You are free to use this Dissertation in any way that is permitted by the copyright and related rights legislation that applies to your use. For other uses you must obtain permission from the rights-holder(s) directly, unless additional rights are indicated by a Creative Commons license in the record and/ or on the work itself. This Dissertation has been accepted for inclusion in WVU Graduate Theses, Dissertations, and Problem Reports collection by an authorized administrator of The Research Repository @ WVU.

For more information, please contact researchrepository@mail.wvu.edu. 


\title{
Using incidental teaching to teach mands to children with autism spectrum disorder
}

\author{
Katherine Louise South Robinson \\ Dissertation submitted \\ to the College of Education and Human Services \\ at West Virginia University \\ in partial fulfillment of the requirements for the degree of \\ Doctor of Education in \\ Educational Psychology \\ Reagan Curtis, Ph.D., Chair \\ Michael Mayton, Ph.D., BCBA-D \\ Patricia Haught, Ph.D. \\ Kimberly Floyd, Ph.D. \\ Trevor Stokes, Ph.D., BCBA-D \\ Department of Learning Sciences and Human Development \\ Morgantown, West Virginia \\ 2018
}

Keywords: autism, applied behavior analysis, incidental teaching, mand training, generalization

Copyright 2018 Katherine S. Robinson 


\begin{abstract}
Using incidental teaching to teach mands to children with autism spectrum disorder
\end{abstract}

\title{
Katherine South Robinson
}

Children with autism display deficits in three core areas; communication, social interaction, and restrictive and repetitive behaviors. Deficits in communication often manifest in the form of maladaptive behaviors that serve to have the individuals needs and wants met. Additionally, children with autism may have difficulty generalizing learned skills to novel environments and with novel items. Naturalistic teaching procedures, such as incidental teaching, can promote generalization through the use of naturally occurring learning opportunities and reinforcers. The purpose of this study is to evaluate an incidental teaching procedure on the acquisition of both rate of manding behavior as well as a generalized mand repertoire. The results of this study indicate that educators can increase language production of students with ASD by creating an environment rich in motivating stimuli, contriving the environment to create situations where the learner initiates toward the instructor and using prompting strategies to expand language production. Rather than anticipating the learners wants/needs and meeting them, using the strategies described in this study will help teachers increase language production and the learner's ability to create novel language, rather than having to teach each concept in isolation as with more analog teaching procedures such as discrete trial training. 
Incidental Teaching to Increase Mands

\section{DEDICATION}

This work is dedicated to the memory and legacy of Dr. Daniel E. Hursh, West Virginia University, Professor Emeritus (1947-2015) 


\section{ACKNOWLEDGEMENTS}

I would like to thank my committee members, Dr. Reagan Curtis, Dr. Michael Mayton, Dr.

Patricia Haught, Dr. Kimberly Floyd and Dr. Trevor Stokes, for the ongoing support and feedback throughout the various phases of the dissertation process. I would especially like to thank my committee chair, Dr. Reagan Curtis for his leadership and encouragement over the past year. Finishing this work would not have been possible without his support and guidance. I would also like to thank Dr. Neal Shambaugh, my former committee chair, who took over as chair for Dr. Dan Hursh's doctoral students, without hesitation, after his passing in 2015. A

special thanks to Dr. Trevor Stokes, my outside committee member of James Madison University, for his mentorship throughout this process, and always reminding me to channel my former mentor Dr. Daniel Hursh.

Thank you to the Department of Learning Sciences and Human Development for awarding me a grant to fund this research.

Completing this process would not have been possible without the support and encouragement of my family over the past 6 years, specifically my husband Courtland Robinson, who has always been a constant system of support in my life, my parents Keith and Deborah South, and my sisters Kristi Vanderburg and Beth Heimbuch, for the moral support throughout this process. 


\section{TABLE OF CONTENTS}

\section{Table of Contents}

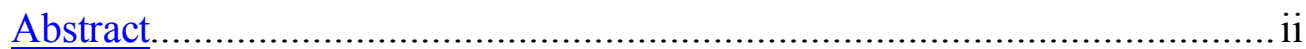

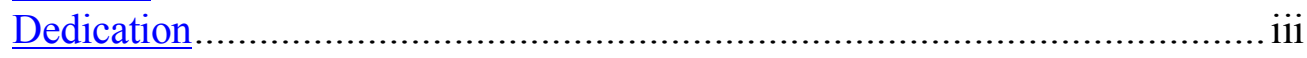

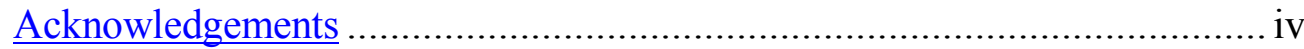

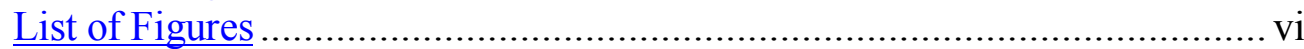

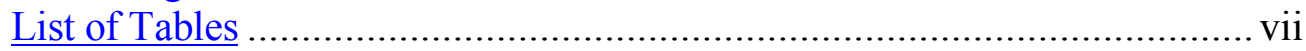

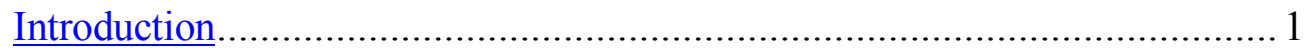

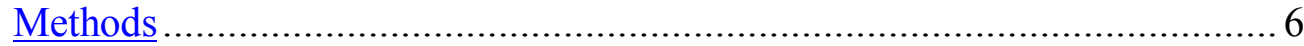

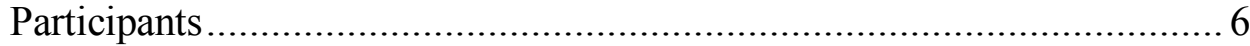

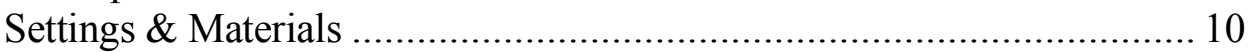

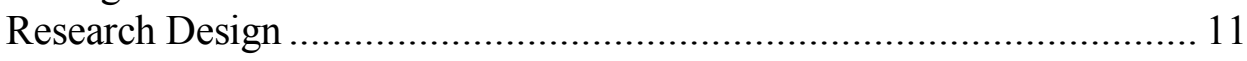

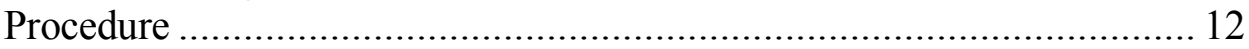

Data Collection \& Analysis............................................................ 15

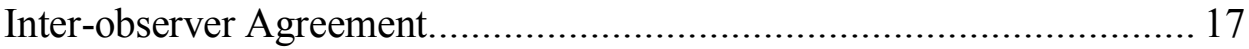

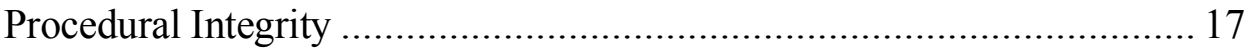

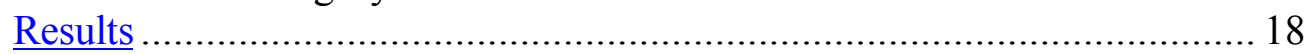

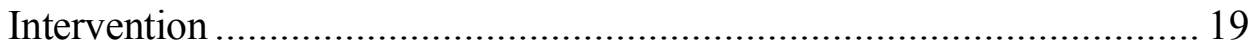

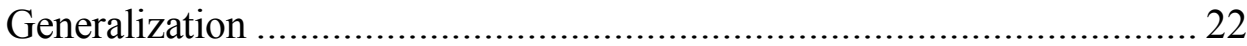

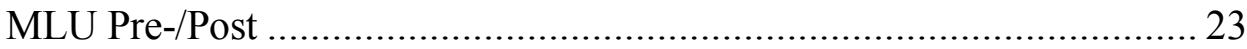

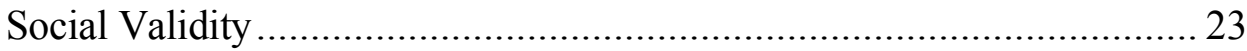

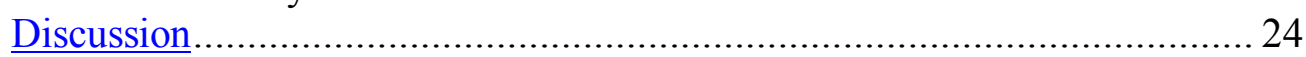

Implications for Future Research ......................................................... 26

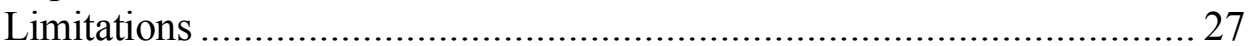

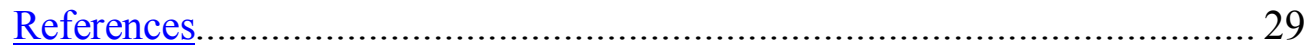

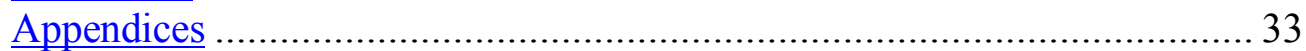

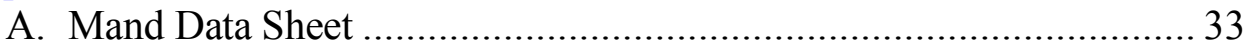

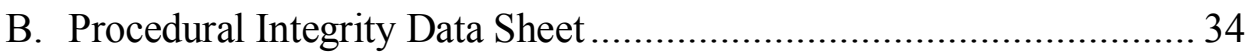

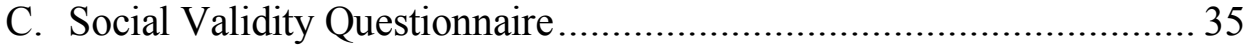


Incidental Teaching to Increase Mands

\section{LIST OF FIGURES}

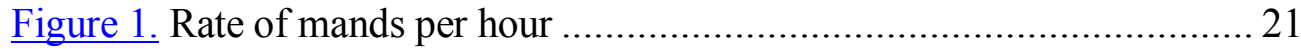

Figure 2. Cumulative number of novel items ............................................ 23 


\section{LIST OF TABLES}

Table 1. Procedural incidental teaching steps.............................................. 15

Table 2. Change in mean level of rate per hour...................................... 21

Table 3. Change in level (percent increase/decrease)............................... 21

Table 4. Average MLU per condition ............................................... 23

Table 5. Social validity questionnaire scores.......................................... 24 


\section{INTRODUCTION}

The Centers for Disease Control and Prevention (2016) estimate that 1 in 68 children (1 in 42 boys, 1 in 189 girls) have autism spectrum disorder (ASD). ASD is a developmental disability which often manifests within the first 3 years of life even if it is not recognized until later. ASD is characterized by impairments in social interaction, communication, and restrictive and repetitive patterns of interest and behaviors (American Psychological Association, 2016). The ability to communicate is a critical life skill and is important in serving to have the child's wants and needs met throughout the course of their day as well as engage in social interactions with other people in their environment (Cowan \& Allen, 2007).

\section{Mands and Mand Training}

Skinner defined a mand as "a verbal operant in which the response is reinforced by a characteristic consequence and is therefore under the functional control of relevant conditions of deprivation or aversive stimulation" (Skinner, 1957, p.36). According to Skinner, a mand specifies the reinforcement (Skinner 1957). Mands are one of the first verbal operants emitted by an individual. In infancy the use vocalizations to alert their caregivers of their needs can quickly be shaped into mands (Skinner 1957; Lee et al., 2014). Therefore, mands are often the first verbal operant taught in a verbal behavior instruction.

In order to fully understand the concept of manding behavior, one has to have an understanding of the term “motivating operations" (MO's). Lee et al. (2014) define motivating operations as "those stimuli or conditions in the environment that exist prior to the emission of a behavior and that function to alter the momentary effectiveness of another stimulus occurring as reinforcement after the emission of the behavior. Relevant MO's serve to occasion the occurrence of mands associated with them" (Lee et al., 2014, p. 416). For example, if someone is 
deprived of food, he or she is more likely to say, "I want food." If someone has been eating a large quantity of salty pretzels without access to a drink he/she is more likely to say, "I need a drink."

Mand training is commonly used in the field of applied behavior analysis (ABA) and the procedure involves arranging a state of deprivation and using the $\mathrm{MO}$ to create an environment ideal for training communication. A target item may be withheld for a certain amount of time prior to mand training sessions to create the $\mathrm{MO}$ and then presented out of reach but within eyesight of the individual learner. The instructor may then provide the learner with a prompt (e.g., "cookie") and deliver the cookie if the learner emits the verbal response "cookie." Mand training is recommended as an essential procedure used in training programs for children with language delays (Lee et al., 2014).

\section{Incidental Teaching, Naturalistic Intervention, and Generalization}

Neely, Rispoli, Gerow, and Hong (2016) identified that incidental teaching is one of the key teaching methods in ABA. Incidental teaching is recognized as an evidence-based practice by both the Behavior Analyst Certification Board (2012) and the National Professional Development Center for Autism Spectrum Disorders (NPDC) (Neely et al., 2016). Incidental teaching was first identified in the research by Hart and Risley (1968) when they described and used incidental teaching procedures to teach descriptive adjectives and spontaneous speech to disadvantaged preschool children. Hart and Risley (1968) described those procedures as arranging the environment to contain known preferred stimuli and activities to motivate the child, waiting for the child to initiate (i.e. reaching, pointing), waiting for the child to respond with a more complex mand, and if they do not, providing prompts to elicit the more complex mand. According to Hsieh, Wilder, and Abellon (2011) incidental teaching is a procedure in 
which stimuli and events are arranged within ongoing daily routines with the goal of motivating children to interact with people in their environment. During the incidental teaching session, the therapist increases the likelihood of responding by contriving MO's in the context of specific interactions. Reinforcers are delivered immediately after each correct response. Franzone (2009) emphasized the importance of the child leading the initiation or interaction. This procedure has been most frequently applied to teach language to children with autism (Hsieh et al., 2011).

Cowan and Allen (2010) conducted a review of research on naturalistic intervention and compared naturalistic procedures to analog teaching procedures such as discrete trial training (DTT). They found some key features of naturalistic procedures include incorporating loosely structured sessions, trials initiated by the child, trials across a variety of settings, stimuli selected by the child, a variety of stimuli utilized across trials, no pre-determined order of responses, and a variety of prompts and incorporating naturally occurring reinforcers. Hart and Risley (1968) initially designed incidental teaching as a naturalistic intervention to "facilitate the generalization and spontaneous use of language in disadvantaged preschoolers (p. 703)." Incidental teaching was not initially developed to be an intervention for children with autism; however, it was modified to meet the social challenges of children with ASD. Roger-Warren and Warren's (1980) article discussed the "mand-model" approach to modify the original incidental teaching procedure. The mand-model approach focused more on the teacher directing the interaction. In this method, as the child is approaching the object, the teacher will tell the child to mand for it and model the exact phrase to use to gain access to the reinforcer. The mand-model approach has been successful in teaching children with autism across multiple settings (Cowan \& Allen, 2007). 
Incidental teaching has been used to teach spontaneous language, multi-word sentences, and descriptive adjectives (Charlop \& Trasowech, 1991; Hart \& Risley, 1968), reciprocal peer interactions (McGeee, Almeida, Sulzer-Azaraoff, \& Feldman, (1992), increased speech intelligibility (Koegel, Camarata, Koegel, Ben-Tal, \& Smith, (1998), and increased social communication (Hancock \& Kaiser, (2002). However, very little research exists on the use of incidental teaching to teach mands. Neely et al. (2016) evaluated virtual coaching as a training package for teaching interventionists to employ incidental teaching strategies. The researchers used a multiple baseline across participants design and evaluated the rate of mands as a secondary effect of the intervention of coaching teachers to use incidental teaching strategies. Their focus was on using pre-selected mands for training, and not on expanding the MLU of mands over time. The results were an increase in level of manding behavior from baseline to treatment, with one of the three students maintaining the skill at two and four-month maintenance probes.

Response generalization is the concept that the learner emits untrained responses that are functionally equivalent to the trained target behavior (Cooper et al., 2007), while some may also refer to the term generalization as the ability to emit a learned behavior or skill across different people, materials, and environments. The focus of this study will be on response generalization as the presence of novel responding as a result of explicit training. In some cases, this may also be referred to as generative responding or language generativity. Stewart et al. (2013) noted that the appearance of novel responding is typically ascribed to the process of generalization and noted that it demonstrates why humans do not need to be taught every response in every circumstance or environment in order to demonstrate skills in novel environments. Language generativity is described as the ability to "produce sentences never before said, and to understand 
sentences never before heard" (p. 137) and is fundamental to the development of fully functional communication (Stewart, McElwee, \& Ming, 2013). In regard to response generalization, Cooper et al. (2007) stated that after all components of an intervention have been terminated, the learner may emit newly acquired target behaviors as well as other functionally related behaviors not observed previously in their repertoire. The term or theory of language generativity has been a challenge in the field of behavior analysis due to the fact there is insufficient theoretical explanation for this phenomenon. The term response generalization, however does provide a technical understanding of this phenomena in the behavioral literature (Stewart et al, 2013). In what is considered a seminal article in the field of applied behavior analysis, Stokes and Baer (1977) defined response generalization as the presence of novel responding and described key features of programming for generalization.

There are a variety of naturalistic interventions (e.g., modeling, mand-model, time delay, incidental teaching) and more analog approaches, like Discrete Trial Training (DTT) to teach mands to children with language delays (Franzone, 2009). Research indicates that the use of naturalistic interventions, specifically incidental teaching, increased the likelihood that the child will generalize and maintain the ability to mand in the future by providing instruction in the natural environment under naturally occurring contingencies. Based on Stokes and Baer (1977) regarding how to program for generalization, incidental teaching was utilized to promote generalized responding and the concept of incidental teaching increased the likelihood that the participants would be able to produce novel language after explicit training. Recommendations from Stokes and Baer (1977) that were incorporated into the current study are train and hope, training sufficient exemplars, train loosely, programing common stimuli and training to generalize or treating generalization as a response and reinforcing occurrences of generalization 
when they happen spontaneously. Stimuli used for training were naturally occurring stimuli present in the participants natural environment (i.e., the classroom). The discriminative stimuli (SD) trained in this study were the presence of the stimuli for which they were motivated to mand and at times the pairing of the echoic prompt from the researcher. Those stimuli were varied (e.g. different types of candy, different types of books) and the language used to prompt was varied as well (e.g. "I want..., "Can you...", "Read me...”).

\section{The Present Study}

The following research questions were utilized to focus on the effects that incidental teaching strategies may have on manding behavior in children with ASD.

1. What is the effect of incidental teaching strategies on the rate of manding behavior?

2. What is the effect of incidental teaching strategies on the development of untrained/novel responses (e.g., response generalization)?

\section{METHODS}

\section{Participants}

The participants of this study were an elementary special education teacher, a special education paraprofessional, and two students with ASD. Upon approval from the [blinded for review] Institutional Review Board (IRB), participants were recruited with flyers that were sent home with all students across three elementary autism classrooms. Consent forms were sent home to all families with the recruitment flyers. For families that spoke and read English as a second language, the school division translator explained the forms to them in Spanish via phone or in person. Baseline data were collected from the participants who returned consent forms, and it was determined that three students had a need for training based on their most recent assessment data and due to their inability to initiate and mand spontaneously, or inability to use 
intelligible and varied language to mand. One student was subsequently removed due to inconsistent attendance. Two learners participated fully in the study, completing all baseline, treatment, and maintenance conditions. Pseudonyms will be used throughout this paper to describe each of the participants.

Students

Jacob was a ten-year-old male diagnosed with ASD at the age of four. At that time, based on teacher report, he displayed significant delays in articulation, receptive language, and expressive language development. He produced early developing consonants and vowels though limited in variety, and speech was characterized by long strings of mostly unintelligible singsong "gibberish". On the PLS-4, Spanish, Jacobs's Total Language Score=53, which is more than 3 standard deviations below the mean. His teacher also reported that Picture Exchange Communication System (PECS) was attempted as an augmentative form of communication when he was in pre-school without success. Jacob's family spoke Spanish as a primary language in the home, but both parents read and spoke English as well. Jacob has been enrolled in school and taught in English since the age of four.

Jacob was identified as a candidate for the study due to his low scores on the Verbal Behavior Milestones Assessment and Placement Program (VB-MAPP), and high scores in certain areas of the Barriers Assessment within the VB-MAPP. In Level 1 (0-18-month range) Jacob scored 0 out 5 possible points in the Mand category, with deficits in emitting 2-word mands, generalizing mands across people, places, and exemplars, spontaneously emitting 5 mands, and emitting a variety of mands without prompts. In Level 2 (18-30-month range) he scored 0 out of 5 in the Mand category, with deficits in manding for at least 20 items, manding with an MLU of 2 words across 10 mands within a 60-minute timed observation, emitting 10 
new mands without training, and manding for 20 different items without prompts. In Level 3 (30-48-month range), he scored 0 out of 5 in the Mand category, with deficits in manding with adjectives, adverbs, prepositions across 10 different mands within a 60-minute timed observation. Barriers to Jacobs's learning identified on the Barriers Assessment are negative behaviors (3 of 4), absent, weak or impaired mand repertoire (score of 4 out of 4 ), prompt dependency (4 out of 4), failure to generalize (4 of 4), weak or atypical MO's (4 of 4), and articulation problems (3 of 4).

Henry was a ten-year-old male diagnosed with ASD at the age of seven and previously was identified as having a developmental delay and speech language impairment at the age of five. At that time, based on teacher report, he displayed a limited repertoire of vowels and consonants. His mother and brother reported that he used /w, k, m, p/. He was observed using vowel sounds or screams to communicate. He was not successful at repeating words and sounds. Henry's language skills appeared to fall in the age range of 6-12 months. Receptively, he was not able to identify objects or pictures when named or follow simple verbal directions. Expressively, Jacob had a vocabulary of two words_- "papa" and "pipi”. His teacher also reported that PECS was attempted as an augmentative form of communication when he was in pre-school without success. Henry's family spoke Spanish as a primary language in the home, but both parents read and spoke English as well. Henry has been enrolled in school and taught in English since the age of five.

Henry was identified as a candidate for the study due to his low scores on the VB-MAPP and high scores in certain areas of the Barriers Assessment within the VB-MAPP. In Level 1 (018-month range) Henry scored 1.5 out 5 possible points in the Mand category, with deficits in generalizing mands across people, places, and exemplars and emitting a variety of mands 
without prompts. In Level 2 (18-30-month range) he scored 0 out of 5 in the Mand category, with deficits in manding for at least 20 items, manding with an MLU of 2 words across 10 mands within a 60-minute timed observation. In Level 3 (30-48-month range), he scored 0 out of 5 in the Mand category, with deficits in manding with adjectives, adverbs, prepositions across 10 different mands within a 60-minute timed observation. Barriers to Henry's learning identified on the Barriers Assessment are an absent, weak or impaired mand repertoire (score of 3 out of 4), prompt dependency (4 out of 4), scrolling responses ( 3 of 4), failure to generalize (3 of 4), and weak or atypical MO's (3 of 4).

\section{Teachers}

The teachers participated in the study by completing social validity questionnaires at the commencement of the study. They did not participate in any of the intervention or data collection throughout the study, but were present as observers in the immediate environment. Teacher A was a licensed special education teacher with 19 years teaching experience. She held a master's in special education and had been teaching in an ASD classroom for 8 years at the time of this study. She had no formal training in ABA but received ongoing coaching and consulting, one day per week from the school divisions Board Certified Behavior Analyst (BCBA). Teacher B was a paraprofessional with less than one year of experience in education and working with ASD at the time of the study. She was also completing a master's degree in elementary education. She had no formal training in ABA but received coaching one day per week, from the school divisions BCBA.

\section{Researchers}

The primary researcher was a doctoral candidate in Educational Psychology at [blinded for review] with 12 years' experience working with children with ASD, and six years' 
experience working in the field of ABA. She was a BCBA and licensed Special Education Teacher, with a master's degree in Teaching and Learning and a bachelor's degree in Spanish. The research assistant was a first-year graduate student at [blinded review] in the Psychological Sciences and ABA master's program. The researchers were responsible for all training implementation and data collection throughout the duration of the study.

\section{Setting \& Materials}

The study took place in a small, diverse public elementary school. The total enrollment of the school division was approximately 6,000 students from preschool to $12^{\text {th }}$ grade, and approximately 680 students qualify for special education services under IDEA. More than 50 languages/dialects and countries of origin are represented by the student body of this school division. The elementary school where the research took place housed the autism and developmental delay (DD) educational programs for the entire school division. Students were placed in these classrooms if their educational needs require a more restrictive environment than a general education classroom with resource special education support provided at other elementary schools in the division.

Both participants were placed in the same self-contained ASD classroom. There was one teacher and one paraprofessional assigned to the classroom with eight total students with ASD or DD. The primary focus of instruction in the classroom was early learning and verbal behavior skills based on individual student needs. Instructional programming focused on basic functional communication, participation, visual-perceptual skills, listener skills, self-help skills and early literacy and math skills. The students participated in inclusion with typically developing, sameage peers during specials (i.e., physical education, art, Spanish, music, library) for one hour per day. 
Materials used in the incidental teaching training sessions were items and activities in the participant's natural environment (i.e., self-contained classroom) or that were identified through a formal preference assessment conducted by the researcher. Items included technology such as the computer, smartboard, and iPads, edibles items such as various types of candy and snacks, tangible items such as books, blankets, pillows, trampoline, puzzles, and physical activities such as walks, tickles, spins, jumps, and pats on the back.

\section{Operational Definitions}

Incidental Teaching was defined as a method of naturalistic teaching that teaches expansion or elaboration on requests the learner is currently able to make (Franzone, 2010; Collins, 2012). Mands were defined as any instance of a participant requesting a preferred item or action by using a gesture, picture exchange, sign, vocal word, or phrase. For the purposes of this study, data were collected on the rate of trained and spontaneous mands as well as the cumulative number of spontaneous mands. Trained mands were defined as any instance of the student successfully echoing, within 3 seconds, the instructor during a training session. Spontaneous mands were defined as any instance of the student making a request that was not formally trained during sessions or was not part of their repertoire previous to the study.

\section{Research Design}

A non-concurrent multiple baseline across participants was used to evaluate the effectiveness of this incidental teaching procedure on the rate of mands per hour as well as the cumulative number of novel items requested by Jacob and Henry across baseline, treatment, and weekly maintenance probe conditions. Multiple baseline designs are often recommended when

there is not the ability to reverse the effects of a treatment once it is implemented. In the case of this research, once taught the skill of manding, the participants could not effectively reverse or 
un-learn that skill and therefore other designs such as an ABAB reversal design would not have been appropriate. Effects of a multiple baseline design are demonstrated by introducing the same intervention to two or more behaviors (within the same participant or across multiple participants), at different times to see if the intervention has the same effect on changing the level and trend of behavior in the treatment conditions (Kazdin, 2011). Non-concurrent multiple baseline designs stagger the timing of baseline and intervention conditions across participants. Non-concurrent multiple baseline designs are often considered less rigorous than concurrent multiple baseline designs, however non-concurrent designs lend themselves well to interventions used in educational settings due to variability in extraneous variables such as time, school schedules, and attendance (Harvey, May, \& Kennedy, 2004). One limitation of standard or concurrent multiple baseline designs that Harvey et al. (2004) discuss is that research may not occur as often in public school settings due to the difficulty in identifying an appropriate research design. In regard to this study, a non-concurrent multiple baseline design was the most appropriate due to inconsistent attendance with one of the participants. Data were not able to be collected on simultaneous days for both participants because one participant was periodically absent from school, therefore a non-concurrent multiple baseline design was the most appropriate.

\section{Procedure}

Sessions. Training sessions were conducted by the primary researcher and occurred in 30-minute increments once per day. The baseline and training sessions were conducted at the same time each day to avoid interference with time in inclusion settings or instructional time in other content areas, as well as to eliminate any variability in data because of the time of day or setting in which training occurred. The physical environment in which training occurred was the 
self-contained autism classroom and was rich in identified preferred stimuli as well as novel items for which the participant may have been motivated to mand.

Baseline. An anecdotal language sample was collected for each participant across a minimum of six, 30-minute baseline sessions or until stable responding was reached. During this condition, anecdotal data were collected on the verbatim statements or gestures participants used to request items or activities from others in their environment. A mean length of utterance (MLU) was calculated based on the average number of words the participant spoke to mand for items and activities in their environment. MLU was used to place participants in a training phase that was at or slightly below their current level of functioning (e.g., two-word MLU meant placement two-word training phase) as well as to monitor their maintenance of the skill in the during weekly maintenance probes.

Preference Assessment. A multiple stimulus without replacement (MSWO) preference assessment was conducted with each participant. Research indicates that preference rankings using MSWO predict reinforcer effectiveness, and that higher preference stimuli are more likely to function as reinforcers than lower preference stimuli (DeLeon \& Iwata, 1996). Up to six items were assessed in any given set. Food and tangible items were assessed in separate sets because food is considered a primary reinforcer. All items were presented equidistant from the participant. The researcher said, "pick one" and allowed the participant to choose. The item that was chosen was either consumed (if food) or given to play for no more than 60 seconds (if tangible), and not replaced into the array of choices presented. The researcher recorded the first item chosen as \#1 on a list of items. The array was rotated prior to the next trial, and the procedure repeated for the second item, third, fourth and so on until all items were chosen. If the participant responded with dis-interest (e.g. throwing the item, putting it back on the table, giving 
the item back the researcher) or makes no response at all, those will be indicated on the hierarchy as well. The results will be indicated by writing the items in numerical order from first to last chosen.

Intervention. Based on baseline and preference assessment data, a set number of explicit training items were identified for each participant. A shaping procedure was used within the treatment condition to systematically increase the length of utterances use to mand. The prompt to increase utterances increased after every second training session (i.e., two training sessions exposed to each shaping phase). The first shaping phase was one-word mands, the second phase was two-word mands with the expansion using the word "want", the third phase expanded by adding "I" before "want", and the fourth phase added an adjective, noun, or verb to expand further. The decision regarding which level of prompting to use was based on the participants MLU in baseline. The primary researcher was responsible for implementing all training sessions. Training sessions occurred with the researcher in close proximity to the participant. The SD's trained were the presence of the motivating stimuli and the researcher used key features of the stimuli to entice the participants to mand. Examples of enticing include crinkling candy wrappers, flipping pages of books in close proximity to the participant, activating toys that made sounds, or hold hands up near shoulders to indicate "tickling" was available. This was done to draw the participants attention to the item, but never in a manner that included any vocal coercion or "bribing". The goal was to train the presence of the item itself as the SD if MO's were present for the child to mand. The researcher intentionally faded (e.g., flipped pages less forcefully to eventually not at all, crinkled wrappers less forcefully to eventually not at all) these enticing qualities with each training session to condition the stimuli alone to function as an SD to mand. The incidental teaching steps and shaping phases were 
created originally by the researcher based on Hart and Risley's (1968), Franzone (2009), and Collins' (2011) recommended steps for implementation of incidental teaching strategies. This procedure is not a replication of any other study on incidental teaching, as little research exists in the area of using incidental teaching to increase mands. The teaching procedure and shaping phases are visible in Table 1.

Table 1. Procedural incidental teaching steps and shaping phases.

\section{Researcher behavior}

1. Arrange environment to elicit mands

a. Hold items in your possession

b. Place items out of reach but in view

c. Sabotage/contrive environment (e.g., unplug, do not offer help)

2. Entice student with known preferred items or activities

a. Activate or show briefly without bribing

3. Wait 3 seconds for the student to initiate toward the instructor, by orienting face and/or body toward the instructor

4. Immediately provide echoic prompt to participant to train new mands for known preferred items and activities according to the current condition phase.

5. If participant does not repeat after 3 attempts, re-entice with a different item or activity.

6. Shaping Phases:

\begin{tabular}{|c|c|c|}
\hline Phase & Trainer Response & Participant Response \\
\hline 1 & "candy" & "candy" \\
\hline 2 & "want candy" & "want candy" \\
\hline 3 & "I want candy" & "I want candy" \\
\hline 4 & "I want red candy" & "I want red candy" \\
\hline
\end{tabular}

7. Systematically fade SD's within session

\section{Data Collection \& Analysis}

\section{Rate per hour of mands}

Data were collected on the rate of mands per hour in baseline, intervention and maintenance, and displayed using a linear graph in a multiple baseline across participants format (Appendix A). Data were visually analyzed (i.e., trend, level, slope, mean, number of data points 
within conditions) to determine a starting point in the training for each participant. A mean level was calculated by determining average rate of mands per hour within each condition (Table 2) as well as calculating the percent increase or decrease from baseline to treatment and treatment to maintenance, as well as the percent increase or decrease within each condition (Table 3), by comparing the difference between the two numbers, dividing by the higher number and multiplying by 100 . Training ended after six sessions followed by weekly maintenance probes. In baseline, stable responding across three sessions was required before training began. Frequency mand data were collected across each training session (30-minute sessions, at least $1 \mathrm{x}$ per day) and then divided by duration (per hour) to calculate rate per hour of mand behavior. Mastery criterion to move to the next phase of training occurred when the participant reached the current target rate in the current training phase across two consecutive training sessions.

\section{Cumulative record of novel items}

Data were collected on the cumulative number of spontaneous mands for novel items during intervention and maintenance to identify the presence of a generalized mand repertoire after explicit training of a set number of items. Any items that were not identified as training items or explicitly trained by the researcher, but emitted by the participant were recorded on the cumulative record. Data were graphed on a linear cumulative record to show the change in slope and level of acquiring novel responding.

\section{Maintenance \& Pre-/Post- MLU Averages}

Weekly maintenance probes were collected on rate per hour of mands after six treatment sessions commenced. Averages of MLU in baseline and maintenance conditions were also calculated to demonstrate development of increased and sustained MLU as a result of the incidental teaching procedure. 


\section{Inter-observer Agreement}

Inter-observer agreement (IOA) data were collected to assess reliability of data collected and detect any potential observer drift (Cooper, Heron, \& Heward, 2007). Both observers observed the same events, recorded data independent of each other, and used the same data sheets during each IOA session. IOA data were calculated using a total count of event recording. According to Cooper et al. (2007), total count IOA is expressed as a percentage of agreement between the total number of responses recorded by two observers and is calculated by dividing the smaller of the counts by the larger count and multiplying by 100 . Current behavioral research methods suggest that IOA be obtained for a minimum of $20 \%$ of sessions and preferably between $25 \%$ and $33 \%$ of session (Cooper et al., 2007), with a score of $80 \%$ or higher across observers.

In Henry's case, IOA data were collected across 52\% (9 of 17) of all sessions (i.e., baseline, treatment, and maintenance) with an average score of 93.2\% agreement across all sessions. In Jacob's case, IOA data were collected across 50\% (7 of 14) of all sessions (i.e., baseline, treatment, and maintenance) with an average score of $92.9 \%$ agreement across all sessions.

\section{Procedural Integrity}

A separate observer evaluated the fidelity of teaching steps by collecting occurrence/nonoccurrence data on the implementation of each teaching step (Appendix B). The second observer is a graduate student in a behavior analysis master's program at the local university. The second observer was approved by the [blinded for review] IRB as a research assistant for this study. She completed the Autism Internet Module for Naturalistic Intervention (Franzone, 2010) as well as reviewed and role-played the incidental teaching procedure with the researcher 
prior to all data collection sessions. Ideal target fidelity implementation is $90 \%$ or higher across all training steps and sessions.

In Henry's case, procedural integrity data were collected across $50 \%$ of treatment sessions (3 of 6) with an average score of 100\% fidelity across all sessions. In Jacob's case, procedural integrity data were collected across $83 \%$ of treatment and sessions (5 of 6 ) with an average score of $100 \%$ fidelity across all sessions.

\section{Social Validity}

Wolf (1978) proposed that clients (i.e., participants, parents, teachers) must understand and admire the goals, outcomes, and methods of an intervention. Cooper et al. (2007) recommended that the social validity of a study in applied behavior analysis be examined in three ways: the social significance of the target behavior, the appropriateness of the procedure and the social importance of the results. For the purposes of this research, social validity was assessed by asking key consumers (teachers of each of the participants) to complete a rating scale questionnaire (Appendix C) to determine the value and social validity in the three areas referenced by Wolf (1978).

\section{RESULTS}

\section{Baseline and Preference Assessment}

Henry demonstrated the ability to mand for several tangible items in baseline, but very few edibles. An MSWO was conducted using edible items, and those items were added to the training items. Ten items were identified as training items or activities for Henry including; book, iPad, read, goldfish, skittles, taffy, computer, help, high-five, and nap. Henry averaged 11.6 mands per hour across 8 baseline sessions (range: 4-16). He averaged an MLU of 1.9 words per mand, therefore he was placed in shaping phase two at the onset of intervention. 
Jacob was able to mand for one total item across six baseline sessions (e.g., five sessions with zero mands, one session with one mand). A formal MSWO preference assessment was conducted with Jacob to identify motivating items and activities for training. The results of his preference assessment indicated that his most preferred items were: tickles, pats (on back), jump (on trampoline), taffy, chocolate, goldfish, glove, book, Dora, and cars. Due to his low rate of responding in baseline, and an MLU of one, the researcher started Jacob started shaping phase one for intervention with the ten items listed above as scripted training items.

\section{Intervention: Rate of mands per hour}

Jacob demonstrated zero vocalizations during the first five baseline sessions and demonstrated two mands per hour in the last baseline session, with an average of .33 mands per hour. The decision to move to treatment even though he did not remain at zero levels, was made based on two extraneous variables. The first variable was attendance. Jacob was scheduled to travel out of the country for one month following holiday break and therefore the timeline to finish treatment and maintenance sessions with him before he left was limited. The second variable was the emergence of problem behavior. Jacob had little to no functional communication skills prior to training, and with the presence of the researcher and research assistant on a daily basis, he began engaging in potentially dangerous problem behavior to gain attention from these additional individuals. His problem behavior included throwing bins of manipulatives on the floor, throwing projectile objects (e.g., staplers, books, etc.), and seeking out and shattering glass objects or objects filled with liquid. With these two variables combined, the researcher decided to begin treatment even though there was a slight increase in manding behavior on the last baseline session. The researcher felt confident there was significant motivation present to increase the overall level of rate of manding behavior in treatment, and that 
change in level is evident within the first treatment session, with a $92 \%$ increase in level (Table 3). The intervention was started with Jacob on the seventh session, while Henry remained in baseline until the ninth session. Jacob had an overall increase in rate per hour of manding behavior of $40 \%$ within the treatment condition, with an average of 30 mands per hour. Jacob showed a $54 \%$ decrease in manding behavior between the last treatment session and the first weekly maintenance probe but showed a $70 \%$ increase in mands per hour within the maintenance condition, with an average of 44 mands per hour.

Henry had relatively stable responding in baseline with an average of 11.6 mands per hour. From baseline to the onset of treatment he showed a 50\% increase in mands per hour. Within treatment he averaged 53 mands per hour and increase his manding behavior by $53 \%$. From the conclusion of treatment to the onset of weekly maintenance probes he showed a $29 \%$ decrease in manding behavior but showed a $13 \%$ increase in mands per hour within the maintenance condition, with an average of 42 mands per hour.

The intervention showed an effect on both participants within the first treatment session (Figure 1; Tables 2 and 3), therefore demonstrating experimental control and the incidental teaching intervention, rather than extraneous variables, accounting for the increase in manding behavior. 


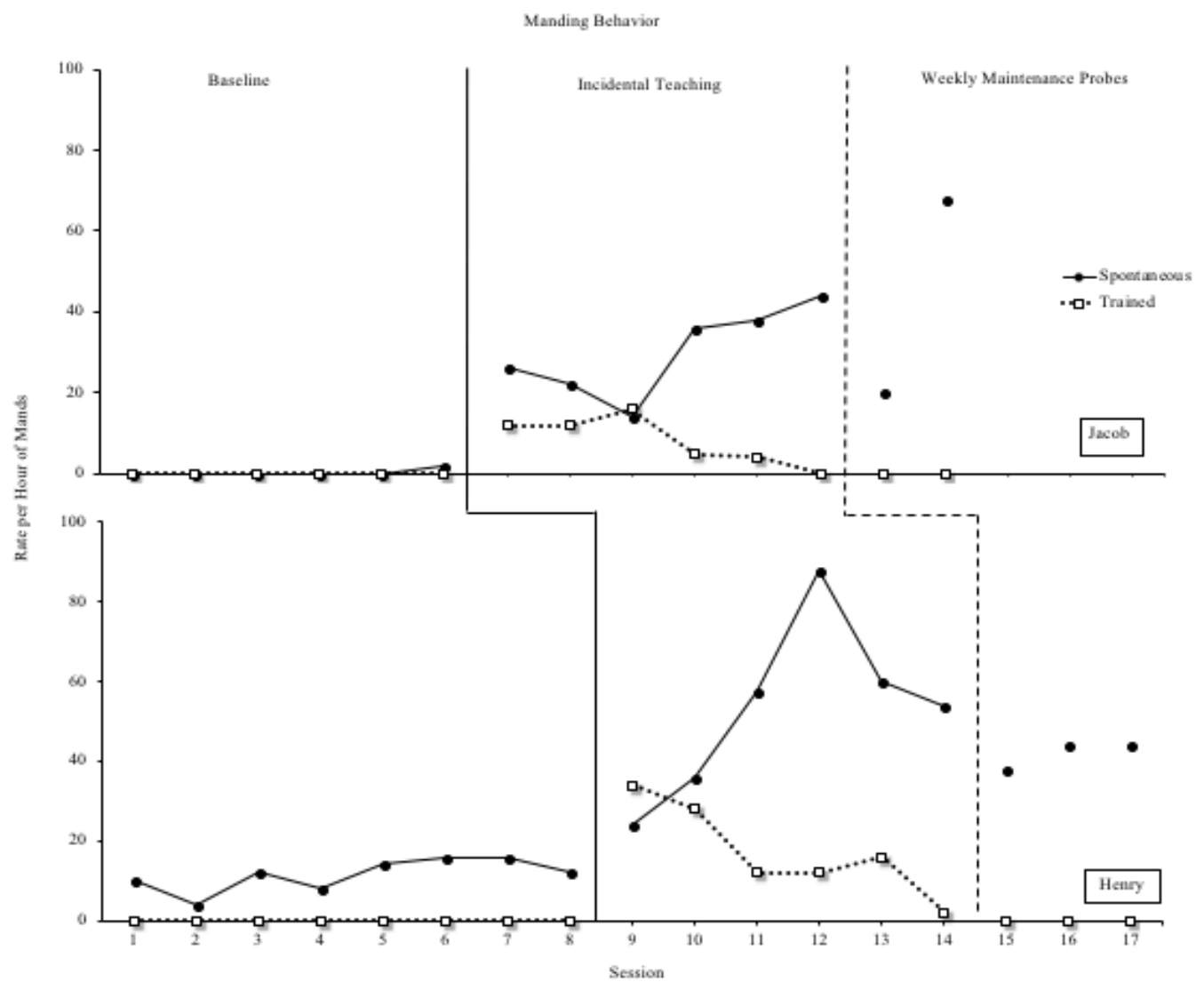

Figure 1. Rate of mands per hour across participants

Table 2. Change in mean level of rate per hour of mands across conditions.

\begin{tabular}{cccc}
\hline Participant & Baseline & Treatment & Maintenance \\
\hline Jacob & .33 & 30 & 44 \\
Henry & 11.6 & 53 & 42 \\
\hline
\end{tabular}

Table 3. Change in level. Percent increase/decrease of rate per hour of mands between and within conditions.

\begin{tabular}{ccccc}
\hline Participant & BL to treatment & Within treatment & $\begin{array}{c}\text { Treatment to } \\
\text { maintenance }\end{array}$ & $\begin{array}{c}\text { Within } \\
\text { maintenance }\end{array}$ \\
\hline Jacob & $+92 \%$ & $+40 \%$ & $-54 \%$ & $+70 \%$ \\
Henry & $+50 \%$ & $+53 \%$ & $-29 \%$ & $+13 \%$ \\
\hline
\end{tabular}




\section{Generalized mand repertoire and generative language}

Each participant had ten pre-selected items for mand training based on their preference assessments and free operant observations in baseline. The data displayed on the cumulative records indicate novel or untrained items for which the participant manded. Henry manded for 17 cumulative items across the 8 baseline sessions. Ten items were chosen for training were based on highest preference ranking during preference assessment. Once treatment began he acquired mands for novel items at a faster rate as indicated by the change in slope of the data on the graph (Figure 2), acquiring 33 novel items in the treatment condition and 2 novel items in the maintenance condition, for a total of 52 novel items acquired across all conditions.

Jacob manded for one item across all six baseline sessions (Figure 2). Once training began with ten pre-selected items, he began acquiring novel items rapidly compared to baseline, as demonstrated by the change in trend and slope once treatment began. He acquired 17 novel items during the treatment condition and zero novel items in maintenance, for a total of 17 novel items across all conditions. Both participants effectively doubled their generalized mand repertoire as a result of this training procedure. 


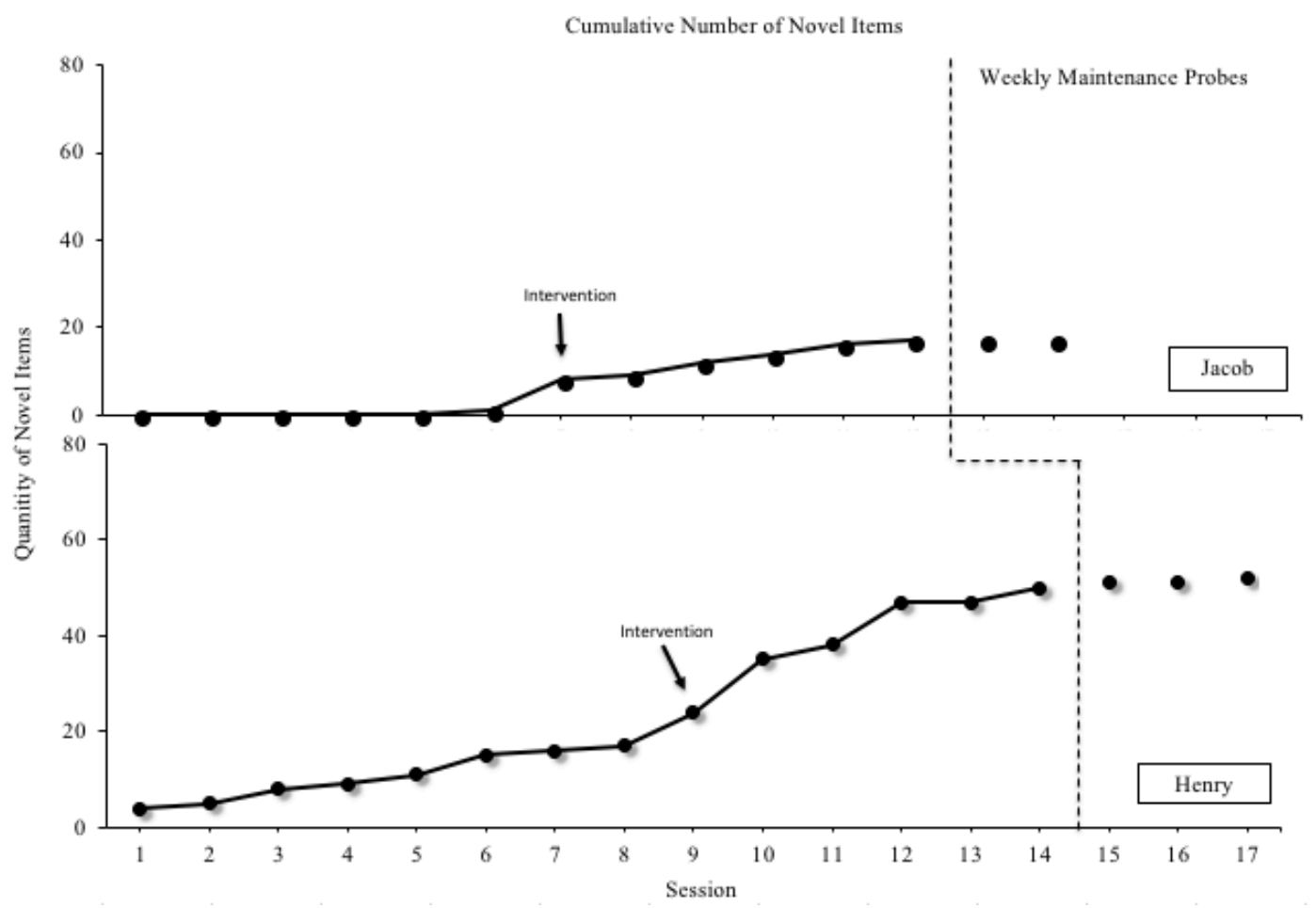

Figure 2. Cumulative number of novel items requested across sessions and participants

\section{MLU Pre-/Post- Averages}

Both Jacob and Henry increased and maintained their overall MLU though training with the incidental teaching procedure (Table 4). Jacob increased and maintained and MLU that was three times that of his baseline levels, and Henry increased and maintained an MLU that was nearly double his baseline levels.

Table 4. Average MLU per condition

\begin{tabular}{ccc}
\hline Participant & Baseline & Maintenance \\
\hline Jacob & 1 & 3.24 \\
Henry & 1.9 & 4.1 \\
\hline
\end{tabular}

\section{Social Validity}

The classroom teacher (Teacher A) and paraprofessional (Teacher B) who worked with the participants were asked to complete a social validity questionnaire (Appendix C) related to the three main areas of the social significance of the target behavior, the appropriateness of the 
procedure and the social importance of the results (Cooper et al., 2007). There were nine positively stated questions (e.g., three from each area) on the questionnaire, with scoring in the form of a rating scale of one to five. One being strongly disagree and five being strongly agree. The questions were all phrased in a positive manner. The results of the questionnaire are presented in Table 5.

Table 5. Social validity (SV) questionnaire scores

\begin{tabular}{ccc}
\hline Participant & $\begin{array}{c}\text { SV points score } \\
(45 \text { possible points })\end{array}$ & SV \% score \\
\hline Teacher A & 45 & $100 \%$ \\
Teacher B & 44 & $97 \%$ \\
\hline
\end{tabular}

The paraprofessional scored eight of nine questions as a five (strongly agree), and one question, "Honoring my students mands quickly is important to helping them acquire this skill" as a four (agree) and left no additional comments. The classroom teacher scored all nines questions as fives's (strongly agree) and made the comment "the teaching procedures proved very effective with the students in the classroom. They learned quickly and continue to use the acquired skills".

\section{DISCUSSION}

Overall, both participants increased the rate of spontaneous mands emitted while the researcher decreased the amount of training trials needed to reach that spontaneous rate in each condition. Training with items that were systematically identified as preferred items created an environment of high motivation for the participant to mand. The researcher cued into very early signs of initiation such as eye gaze, physical approach, and gestures to use as opportunities to provide mand training. The environment was one that was rich in previously identified preferred items as well as novel items with similar qualities (i.e., taste, texture, feel, sound), and this 
created ideal conditions for training as well as the development of a generalize mand repertoire. Both participants increased the number of novel items they requested throughout training and maintenance. They did so without any explicit training for those novel items. These results are consistent with research that exists on naturalistic interventions. Koegel, Carter, and Koegel (2003) incorporated diverse training environments, motivating stimuli, and trained learner initiations. The researcher found growth in untrained responding, generalization across settings, and an increase in the overall mean length of utterance emitted by the participants. The results are also consistent with the recommendations of Stokes and Baer (1977) regarding how to program for generalized responding.

The multiple baseline across participants design lent itself well this type intervention because the participants did not have the ability to unlearn the skills taught, and therefore a reversal design would not be appropriate. Also, the non-concurrent multiple baseline lent itself to use in an applied setting such as a school where variable such as student attendance were not predictable. The cumulative record of novel responses emitted is an accurate measure of the impact of this intervention on the generalized mand repertoire. Both participants displayed increases in the accumulation of novel responding from baseline to intervention and the trend at which novel responses were emitted in each of the conditions is an indicator of how quickly new language was acquired. Henry (Figure 2) had significant changes in the trend of novel responding acquisition. While Jacob (Figure 2) did not acquire novel language as quickly, you can still see an increase in the rate at which he acquired novel language as compared to baseline. The cumulative record has a long history of use within the field of behaviorism. That history can be traced back to experimental analysis of behavior in animal laboratories. It is the only standardized measure used in single-case research design. In applied research cumulative 
records are not as frequently used but lend themselves well to data that need to be tracked in terms of accumulation of multiple responses, i.e. accumulated words, phonemic sounds, and issues of social impact (Kazdin, 2011).

The results of this study and prior research indicate that educators can increase language production of students with ASD by creating an environment rich in motivating stimuli, contriving the environment to create situations where the learner initiates toward the instructor and using prompting strategies to expand language production. Rather than anticipating the learners wants and needs and meeting them, using the strategies described in this study will help teachers increase language production and increase the learner's ability to create novel language, rather than having to teach each concept in isolation as with more analog teaching procedures such as discrete trial training.

\section{Implications for future practice and research}

Teachers have access to their students for six to seven hours per day and countless opportunities to embed learning opportunities in their environments during that time. If teachers understand how to assess student preference, look for naturally occurring opportunities to contrive a student's environment and embed MO's, it will encourage the student to respond to relevant SD's in their environment rather than relying on teachers to meeting their needs or prompt them to mand. This is a simple teaching procedure that does not take copious amounts of training, time or money to implement as it only requires materials found in the students' natural environment.

Future areas of research should include replication of this study (at least additional replications) across more participants as there is little research on the use of incidental teaching to teach mands and this is an original teaching procedure. Future replications should include 
tracking generalization of the acquired responses across settings as well initiations toward multiple people in their environment, and whether mands increased outside of the training environment (i.e., home, community, other settings within the school building). Further expansion of research on more novel forms of intraverbal exchanges may be a more functional language goal and lend itself to further development of a generalized mand repertoire. For example, rather than teaching a learner to ask for a specific stimulus visible but out of reach in their environment, teaching the leaner to ask for information about their environment and items that may not be visible or present may be a more functional skill. Although it was not an independent variable that was measured in this study, based on teacher report the participants problem behavior decreased overall as a result of having a higher level of manding behavior. Future research should include data collection on problem behavior and the effects which teaching mands has on decreasing problem behavior. Additionally, research on coaching teachers to use incidental teaching to increase mands would also be beneficial to add to the field of ABA.

\section{Limitations}

Limitations to this study included student attrition from the study due to inconsistent attendance, the small number of participants, and the limited age range of the participants. The school division has a very transient population in which students and families move frequently, and several students in the identified classrooms also have medical diagnoses that interfere with their attendance. The study included a small number of participants $(\mathrm{N}=2)$, both in the $4^{\text {th }}$ grade, so the outcomes of this study are limited in terms of consistency of outcomes for this age range and the lack of research for secondary grade levels. Additionally, the small number of participants does not establish generalizability unless the same procedure could be replicated 
across more participants in the future. Another limitation of this study is that social validity and generalization data were not able to be collected beyond the school environment. Parents were often difficult to make contact with. In an applied setting such as public-school classroom, there are many extraneous variables that can affect the changes in behavior. In this case, the teachers in the classroom did not receive training on how to implement the intervention during the study, however using their own observational learning skills, they may have been imitating the researcher's behavior when the researcher was not present, having an effect on the increase in manding behavior overall. 


\section{REFERENCES}

American Psychological Association (2016). Retrieved November 27, 2011, from http://www.apa.org/topics/autism/

Behavior Analyst Certification Board. (2012). Fourth edition task list. Retrieved from http://bacb.com/wp-content/uploads/2016/03/160101-BCBA-BCaBA-task-list-fourthedition-english.pdf

Centers for Disease Control (2016). “Autism Spectrum Disorders (ASD)”. Retrieved November 27, 2016, from http://www.cdc.gov/ncbddd/autism/data.html

Centers for Disease Control (2016). "Developmental Disabilities”. Retrieved November 27, 2011, from https://www.cdc.gov/ncbddd/developmentaldisabilities/facts.html

Charlop, M. H., \& Trasowech, J. E. (1991). Increasing autistic children's daily spontaneous speech. Journal of Applied Behavior Analysis, 24(4), 747-761.

Charlop, M. H., \& Walsh, M. E. (1986). Increasing autistic children's spontaneous verbalizations of affection: An assessment of time delay and peer modeling procedures. Journal of Applied Behavior Analysis, 19(3), 307-314.

Collins, B. C. (2012). Systematic instruction for students with moderate and severe disabilities. Baltimore, MD: Paul H. Brookes Publishing Company.

Cooper, J. O., Heron, T. E., \& Heward, W. L. (2007). Applied behavior analysis. Boston, MA. $2^{\text {nd }}$ Edition. Pearson Education, Inc.

Cowan, R. J., \& Allen, K. D. (2007). Using naturalistic procedures to enhance learning in individuals with autism: A focus on generalized teaching within the school setting. Psychology in the Schools, 44(7), 701-715. 
DeLeon, I. G., \& Iwata, B. A. (1996). Evaluation of a multiple-stimulus presentation format for assessing reinforcer preferences. Journal of Applied Behavior Analysis, 29, 519-532.

Franzone, E. (2009). Naturalistic intervention: Steps for implementation. Madison, WI: The National Professional Development Center on Autism Spectrum Disorders, Waisman Center, University of Wisconsin.

Franzone, E. (2010). Naturalistic intervention for children and youth with autism spectrum disorders: Online Training Module. (Madison, WI: National Professional Development Center on Autism Spectrum Disorder, Waisman Center, The University of Wisconsin). In Ohio Center for Autism and Low Incidence (OCALI), Autism Internet Modules, www.autisminternetmodules.org. Columbus, OH: OCALI.

Hancock, T. B., \& Kaiser, A. P. (2002). The effects of trainer-implemented enhanced milieu intervention on the social communication of children with autism. Topics in Early Childhood Special Education, 22(1), 39-54.

Hart, B. M. \& Risley, T. R. (1968). Establishing use of descriptive adjectives in the spontaneous speech of disadvantaged preschool children. The Journal of Applied Behavior Analysis, 1, $109-120$.

Harvey, M. T., May, M. E., \& Kennedy C. H., (2004). Nonconcurrent multiple baseline designs and the evaluation of educational systems. Journal of Behavioral Education, 13(4), 267276.

Hsieh, H. H., Wilder, D. A., \& Abellon, O. E. (2011). The effects of training on caregiver implementation of incidental teaching. Journal of Applied Behavior Analysis, 44(1), 199203. 
Kazdin, A. (2011). Single-case research designs (2nd ed.). New York, NY: Oxford University Press.

Koegel, L.K., Carter, C.M., \& Koegel, R.L. (2003). Teaching children with autism selfinitiation as a pivotal response. Topics in Language Disorders, 23, 134-145.

Koegel, R. L., Camarata, S., Koegel, L. K., Ben-Tall, A., \& Smith, A. E. (1998). Increasing speech intelligibility in children with autism. Journal of Autism and Developmental Disorders, 28(3), 241-251.

Lee, G., Luke, N., \& LeePark, H. (2014). Using mand training to increase vocalization rates in infants. Psychological Record, 64, 415-421.

McGee, G. G., Almeida, M. C., Sulzer-Azaroff, B., \& Feldman, R. S. (1992). Promoting reciprocal teaching via peer incidental teaching. Journal of Applied Behavior Analysis, $25,117-126$.

McGee, G. G., Krantz, P. J., \& McClannahan, L. E. (1985). The facilitative effects of incidental teaching on preposition use by autistic children. Journal of Applied Behavior Analysis, $18,17-31$

Neely, L., Rispoli, M., Gerow, S., \& Hong, E. (2016). Preparing interventionists via telepractice in incidental teaching for children with autism. Journal of Behavioral Education, 25, $393-416$.

Rogers-Warren, A., \& Warren, S. F. (1980). Mands for verbalizations: Facilitating the display of newly trained language in children. Behavior Modification, 4, 361-382.

Skinner, B. F. (1957). Verbal behavior. New York. Prentice Hall.

Stewart, I., McElwee, J., \& Ming, S. (2013). Language generativity, response generalization, and derived relational responding. The Analysis of Verbal Behavior, 29, 137-155. 
Incidental Teaching to Increase Mands

Stokes, T. F., \& Baer, D. (1977). An implicit technology of generalization. The Journal of Applied Behavior Analysis, 10, 349-367.

Sundberg, Mark L. (2008) VB-MAPP Verbal Behavior Milestones Assessment and Placement Program: a language and social skills assessment program for children with autism or other developmental disabilities: guide Concord, CA: AVB Press

Wolf, M. M., (1978). Social Validitiy: The case for subjective measurement or how applied behavior analysis is finding its heart. Journal of Applied Behavior Analysis, 11, 203-214. 


\section{APPENDICES}

Appendix A: Data Sheet (baseline \& intervention)

Daily Mand Training Data Sheet

Pseudonym:

Date:

Time:

Setting:

Session:

Condition Phase:

\begin{tabular}{|l|l|l|l|l|}
\hline Trial & Anecdotal Recording (word for word) & SI & P & T \\
\hline 1 & & & & \\
\hline 2 & & & & \\
\hline 3 & & & & \\
\hline 4 & & & & \\
\hline 5 & & & & \\
\hline 6 & & & & \\
\hline 7 & & & & \\
\hline 8 & & & & \\
\hline 9 & & & & \\
\hline 10 & & & & \\
\hline 11 & & & & \\
\hline 12 & & & & \\
\hline 13 & & & & \\
\hline 14 & & & & \\
\hline 15 & & & & \\
\hline 16 & & & & \\
\hline 17 & & & & \\
\hline 18 & & & & \\
\hline 19 & & & & \\
\hline 20 & & & & \\
\hline 21 & & & & \\
\hline 22 & & & & \\
\hline 23 & & & & \\
\hline 24 & & & & \\
\hline 25 & & & & \\
\hline & Total mands & & & \\
\hline & Total items requested & & & \\
\hline & Total NEW items & & & \\
\hline
\end{tabular}

Trained mand: any instance of student echoing a prompt that an instructor has given her.

Spontaneous mand: any instance of student requesting without prompting from the instructor.

$\mathrm{SI}=$ Spontaneous/Independent

$\mathrm{P}=$ Prompted-student initiates with gestures or lesser form of mand, and teacher says "what do you want" or "tell me what you want".

$\mathrm{T}=$ Trained-explicitly part of training trial 
Appendix B: Implementation Fidelity Checklist

Procedural Integrity Data Sheet

Incidental Teaching/Mand Training Implementation

Date:

Session:

Implementer:

Setting:

Fidelity Observer:

Participant Pseudonym:

\begin{tabular}{|c|c|c|c|c|c|c|c|c|c|c|}
\hline \multirow[t]{2}{*}{ Component } & \multicolumn{10}{|c|}{ Trials } \\
\hline & 1 & 2 & 3 & 4 & 5 & 6 & 7 & 8 & 9 & 10 \\
\hline \multicolumn{11}{|c|}{ 1. Arrange environment to elicit mands } \\
\hline \multicolumn{11}{|c|}{ Hold item in possession but in view } \\
\hline \multicolumn{11}{|c|}{ place item out of reach but in view } \\
\hline \multicolumn{11}{|c|}{$\begin{array}{l}\text { sabotage environment (unplug, remove } \\
\text { batteries, etc) }\end{array}$} \\
\hline \multicolumn{11}{|c|}{$\begin{array}{l}\text { 2. Entice with known preferred items or } \\
\text { activities }\end{array}$} \\
\hline \multicolumn{11}{|c|}{ activate or show briefly } \\
\hline \multicolumn{11}{|c|}{$\begin{array}{l}\text { 3. Wait } 5 \text { seconds for student to initiate } \\
\text { toward instructor }\end{array}$} \\
\hline \multicolumn{11}{|c|}{$\begin{array}{l}\text { 1. provide echoic prompt to train new } \\
\text { mand }\end{array}$} \\
\hline \multicolumn{11}{|c|}{ 5. Followed current training level } \\
\hline \multicolumn{11}{|c|}{$\overline{\text { 6. Followed student work break schedule }}$} \\
\hline \multicolumn{11}{|c|}{ 7. Collected data immediately } \\
\hline \multicolumn{11}{|c|}{ Frequency of trained vs spontaneous } \\
\hline \multicolumn{11}{|c|}{ Anecdotal recording of mands } \\
\hline \multicolumn{11}{|l|}{ Total } \\
\hline \multicolumn{11}{|l|}{ Total Correct } \\
\hline \% correct & & & & & & & & & & \\
\hline
\end{tabular}


Appendix C: Social Validity Questionnaire

\section{Teacher Social Validity Questionnaire/Survey}

Please rate the following on a scale of 1 (strongly disagree) to 5 (strongly agree).

\begin{tabular}{|c|c|c|c|c|c|}
\hline & $\begin{array}{c}1 \\
\text { Strongly } \\
\text { disagree }\end{array}$ & 2 & 3 & 4 & $\begin{array}{l}\quad 5 \\
\text { Strongly } \\
\text { Agree }\end{array}$ \\
\hline $\begin{array}{l}\text { 1. Teaching students to mand (request) } \\
\text { for items and objects in their } \\
\text { environment is an important skill for } \\
\text { my student to demonstrate. }\end{array}$ & & & & & \\
\hline $\begin{array}{l}\text { 2. Expanding mands (requests) to include } \\
\text { adjectives and verbs is an important } \\
\text { skill for my student to demonstrate. }\end{array}$ & & & & & \\
\hline $\begin{array}{l}\text { 3. Manding (requesting) helps my } \\
\text { students integrate more readily into the } \\
\text { general education population with } \\
\text { peers and teachers. }\end{array}$ & & & & & \\
\hline $\begin{array}{l}\text { 4. Honoring my students mands } \\
\text { (requests) quickly is important in } \\
\text { helping them acquire this skill. }\end{array}$ & & & & & \\
\hline $\begin{array}{l}\text { 5. The sessions were not intrusive to my } \\
\text { student's daily routine. }\end{array}$ & & & & & \\
\hline $\begin{array}{l}\text { 6. My student demonstrated an increase } \\
\text { in his/her ability to mand to have } \\
\text { needs and wants met. }\end{array}$ & & & & & \\
\hline $\begin{array}{l}\text { 7. Implementing incidental teaching } \\
\text { procedures is an effective way to teach } \\
\text { mands to students with developmental } \\
\text { disabilities and/or autism. }\end{array}$ & & & & & \\
\hline $\begin{array}{l}\text { 8. Implementing incidental teaching } \\
\text { procedures in the natural environment } \\
\text { has helped my student generalize the } \\
\text { skill to other settings without explicit } \\
\text { training. }\end{array}$ & & & & & \\
\hline $\begin{array}{l}\text { 9. Implementing incidental teaching } \\
\text { procedures is a cost-effective way to } \\
\text { teach the skill of manding. }\end{array}$ & & & & & \\
\hline
\end{tabular}


Incidental Teaching to Increase Mands

Comments: 